\title{
Multiscale Modelling in MAterials SCIENCE
}

\author{
AgIC, A. \& FiLIPAN, V.
}

Abstract: The multiscale simulation strategies bridge the models and simulation techniques across a broad range of length and time scales. Several simulation techniques, each one suited for a particular length and time scale, are briefly commented. The quasicontinuum (QC) as one of multiscale methods, which combine atomistic simulation with coarse-graining schemes is described in details and used for an illustrative example (nanoindentation of single Ni crystal with spherical indenter). The original QC code and the procedure based on the concept of mean force potentials were used for modelling. The results of simulation are compared with the data from literature especially for the material elastic constants. The model also enables predictions of materials behaviour outside the range of experiment, and therefore it will be improved and used for further investigations in materials science field. The future work will be directed toward including temperature dependences and speeding up the numerical procedure.

Key words: multiscale modelling, quasicontinuum, nanoindentation
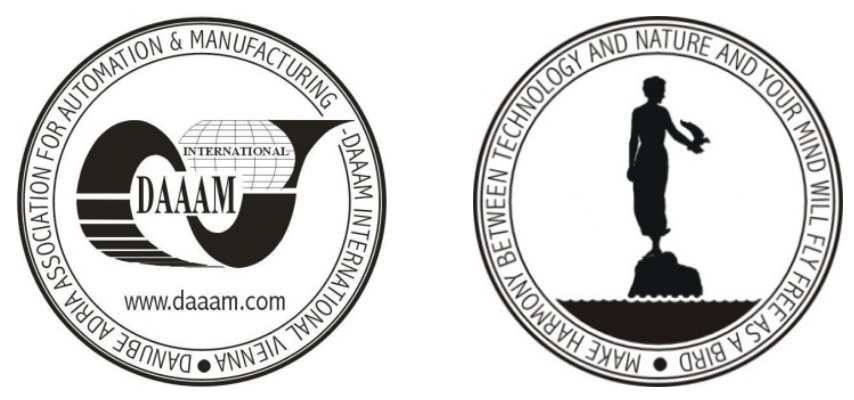

Authors' data: Prof. Agic, A[nte]*; Asoc. Prof. Dr. Filipan,V[eljko]**, *Faculty of Chemical Engineering \& Technology, Jelekovići 11C, 10000, Zagreb, HR, **Faculty of Chemical Engineering \& Technology, B.Buića 25, 10000, Zagreb, HR, aagic@fkit.hr, vfilipan@fkit.hr

This Publication has to be referred as: Agic, A[nte] \& Filipan, V[eljko] (2008). Multiscale Modelling in Materials Science, Chapter 01 in DAAAM International Scientific Book 2008, pp. 001-014, B. Katalinic (Ed.), Published by DAAAM International, ISBN 978-3-901509-66-7, ISSN 1726-9687, Vienna, Austria

DOI: $10.2507 /$ daaam.scibook.2008.01 